\title{
Gradhiva
}

GRADHIV

Revue d'anthropologie et d'histoire des arts

$31 \mid 2020$

L'idéal du musicien et l'âpreté du monde

\section{Vivre ensemble en Colombie? Le Plan Nacional de Música para la Convivencia (2002)}

Living Together in Colombia? The Plan Nacional de Música para la Convivencia (2002)

Jaime A. Salazar

\section{OpenEdition}

Journals

Édition électronique

URL : http://journals.openedition.org/gradhiva/5072

DOI : 10.4000/gradhiva.5072

ISSN : 1760-849X

Éditeur

Musée du quai Branly Jacques Chirac

Édition imprimée

Date de publication : 2 septembre 2020

Pagination : 92-111

ISBN : 978-2-35744-131-6

ISSN : 0764-8928

\section{Référence électronique}

Jaime A. Salazar, «Vivre ensemble en Colombie? Le Plan Nacional de Música para la Convivencia

(2002) », Gradhiva [En ligne], 31 | 2020, mis en ligne le 31 mars 2021, consulté le 01 avril 2021. URL

http://journals.openedition.org/gradhiva/5072 ; DOI : https://doi.org/10.4000/gradhiva.5072 


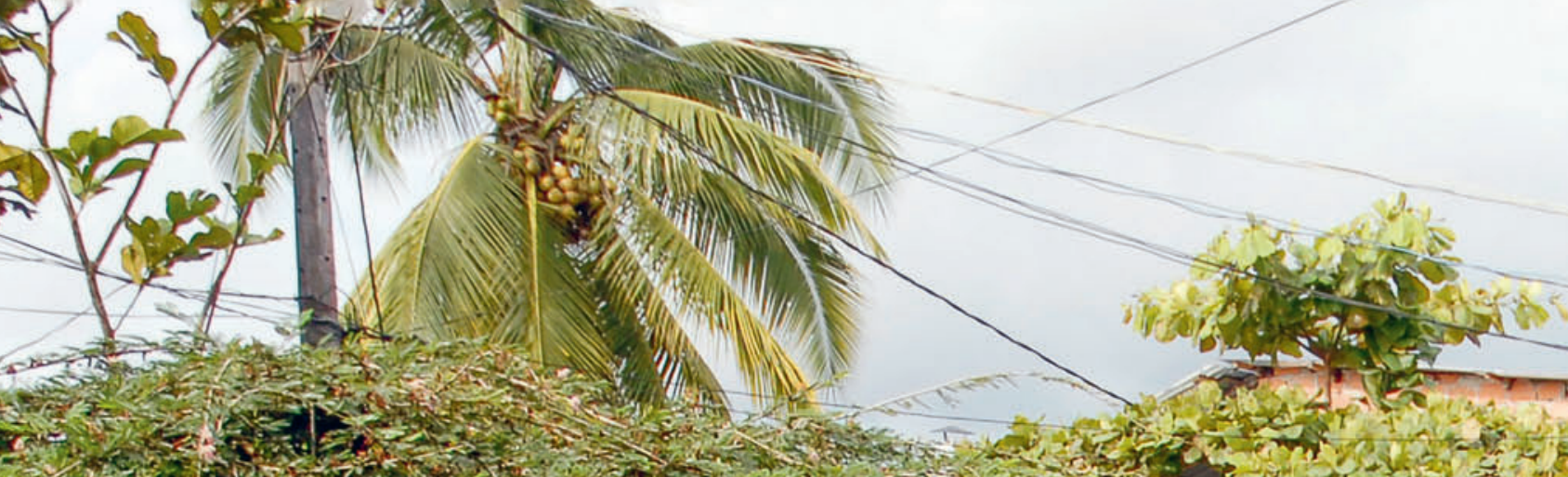


Vivre ensemble

en Colombie?

Le Plan Nacional

de Música para

la Convivencia

(2002)

\section{Jaime \\ A. Salazar}


Au cours des dernières décennies, le ministère colombien de la Culture a élaboré une série de plans visant à faire de la musique l'instrument d'une paix sociale qui reste largement à construire, et l'outil avec lequel se forge l'image d'une Colombie riche de sa diversité culturelle. Ces politiques visaient à compenser la violence des affrontements militaires de longue date. Nous analysons ici trois de ces plans produits entre 2000 et 2006, après avoir conduit une enquête auprès du ministère de la Culture pour analyser la façon dont la musique a été inscrite à l'agenda politique. Le Plan Nacional de Música para la Convivencia de 2002 est au cour de cette analyse.

1. La Colombie compte aujourd'hui près de 50 millions d'habitants. D'après les analyse conduites par le HautCommissariat des Nations unies pour les réfugiés (UNHCR) en 2018, on estime à 7,7 millions le nombre de personnes en déplacement forcé. Ces déplacements sont de caractère rural-urbain, mais aussi intra-urbain, avec une installation des personnes visées dans la périphérie des grandes agglomérations. Voir Oficina del Alto

Comisionado de las Naciones Unidas para los Refugiados (Acnur), «Fact Sheet, Colombia Septiembre 2018» [en ligne], disponible sur: https://www. acnur.org/op/op_fs/5b97f3154 /hoja-informativa-acnur-en-

colombia-2018.html

(consulté en juin 2019).

2. Sauf mention contraire, tout au long de cet article, les traductions destextes

3. La politique de sécurité démocratique du gouvernement Uribe s'est construite suivant trois axes: 1) la poursuite de I'offensive contre les Farc: 2) une «politique de paix» avec les paramilitaires; 3) des mesures spécifiques - telles que les soldats paysans, les incitations à la désertion et les réseaux d'informateurs destinées à appuyer les deux autres. Voir Cante 2003; Lea autres. Voir Cante 2003; Leal 2009; Angarita Cañas 2011; Espinosa Zuluaga 2017; Ríos Sierra 2016: 355-452.
Depuis près d'un siècle, l'histoire de la Colombie est marquée par une récurrence de conflits armés d'une grande violence. Celle-ci fut d'une telle intensité dans les années 1946-1960 que les historiens usent d'une qualification éponyme pour désigner ce moment de l'histoire colombienne: La Violencia. Ces conflits se poursuivent aujourd'hui encore sous une forme quelque peu atténuée. Ils sont à la fois politiques, ethniques, régionaux, économiques, et de classes. Les filiations politiques apparaissent comme des marqueurs de discrimination clanique, c'est ce qui fait que cette violence endémique s'apparente à une guerre civile. Malgré l'accord historique signé à Bogotá le 24 novembre 2016 entre les Forces armées révolutionnaires de Colombie (Farc) et le gouvernement colombien, qui marquait la fin de cinquante-trois ans de conflit armé, la Colombie est toujours en proie à ces affrontements récurrents mêlés à ceux en lien avec le trafic de produits illicites. La société colombienne est déchirée par cette violence: la Colombie est le pays au monde qui compte le plus de déplacés internes, appelés los desplazados ${ }^{1}$.

Les politiques successives mises en œuvre par la République font donc de l'établissement d'un État de droit au service d'une paix durable leur priorité absolue. Toutes réaffirment la légitimité de la violence d'État et œuvrent à un renforcement des moyens militaires et policiers. Ces mesures répressives s'accompagnent de plans d'intégration sociale. C'est dans ce cadre que, d'une façon tout aussi récurrente, la musique est convoquée pour œuvrer à la construction d'une paix sociale. La présente contribution s'intéresse à cet aspect singulier des politiques culturelles, à la façon dont la musique est mobilisée par le gouvernement colombien pour renforcer le lien social et construire l'image d'une Colombie riche de sa diversité culturelle. Ainsi le ministère de la Culture se voit-il régulièrement chargé d'élaborer des planes allant dans ce sens.

C'est à cet endroit que je vais me situer ici en étudiant plus particulièrement le Plan Nacional de Música para la Convivencia (Plan national de la musique pour le vivre-ensemble) mis en œuvre par la direction de la Musique du ministère de la Culture de Colombie en 2002, qui cherche à «mettre en place une politique d'État pour la musique qui contribue à renforcer l'expression musicale individuelle et collective comme facteur de construction de citoyenneté 2 » (Ministerio de Cultura de Colombia 2003: 2) dans un contexte de sécurité démocratique ${ }^{3}$.

L'examen de trois textes qui ont inauguré cette politique jalonne cette contribution. Ils ont en commun de s'appeler «Plan», sans pour autant revêtir un même statut:

- le Plan Nacional de Cultura 2001-2010 (PNG), loi votée par le Congrès ;

- le Plan Nacional de Desarrollo 2002-2006, Hacia un Estado Comunitario (PND 2002-2006), texte-cadre;

- le Plan Nacional de Música para la Convivencia (PNMC), qui est enchâssé dans le PND et est l'un des axes de la politique culturelle prônée par le PND.

L'analyse de ces textes de loi est suivie d'une enquête de terrain que j'ai menée au sein du ministère de la Culture de Colombie. Entre 2012 et 2018, j'ai pu en effet réaliser vingt-deux entretiens auprès de ses fonctionnaires. J'ai exploré quelques bilans et des documents de travail de l'Área de Música de la Dirección de Artes, ainsi que des publications du ministère de la Culture et des gouvernements qui ont à voir avec le PNMC.

\section{EL PLAN NACIONAL DE CULTURA} (2000)

Le Plan Nacional de Cultura est élaboré par le ministère de la Culture et publié au mois de juillet de l'an 2000. Rappel du contexte.

En 1998, le conservateur Andrés Pastrana est élu à la présidence du pays. Avec l'appui de l'Administration américaine, il lance aussitôt le «plan Colombie pour la paix, la prospérité et le renforcement de l'État». Son action en faveur de la paix, il la conduit dans le sud-ouest du pays, à San Vicente del Caǵuán. 
À la veille de son élection, il avait élaboré avec Manuel Marulanda, fondateur et commandant en chef des Farc 4 , un accord visant l'instauration d'une vaste zone démilitarisée - zona de distensión - dans la région du Caguán 5 .

En janvier 1999, il se déplace en personne à San Vicente del Caguán (Caquetá) pour marquer solennellement l'ouverture du processus de discussion. De nombreuses représentations diplomatiques sont présentes. Mais à la surprise générale, Manuel Marulanda n'est pas là et son discours est lu par l'un des commandants. Dès ce moment, et pour les quatre années qui vont suivre, «une large partie de l'opinion qui militait en faveur d'une solution négociée au conflit accuse les Farc d'être responsables de l'échec» (Pécaut 2006 : 29). En 2002, après quatre années de négociations et un constat d'échec de ce dialoǵue de paix, «la déception est encore plus grande et va entraîner le ralliement massif à la candidature d'Álvaro Uribe, partisan de la guerre frontale contre la guérilla» (ibid.: 35).

C'est dans ce contexte de grandes tensions politiques et militaires que le gouvernement national a recours à la culture pour en faire un outil de cohésion nationale et de restauration du lien social. La séquence dont il va être ici question s'ouvre au milieu du mandat du président Pastrana.

En juillet 2000, le ministère de la Culture et le Consejo Nacional de Cultura 6 (CNC) travaillent de concert à l'élaboration d'un plan décennal. Ils viennent de réaliser une consultation citoyenne auprès de vingttrois mille Colombiens (Ministerio de Cultura de Colombia 2007). Celle-ci doit permettre de mesurer les attentes des acteurs locaux à l'égard de la politique culturelle de l'État. Elle vise en même temps à concevoir des politiques publiques capables de garantir la durabilité et la soutenabilité 7 du secteur culturel. Son mode d'élaboration «citoyen» s'inscrit dans la continuité de l'élan de démocratie participative qui a caractérisé la Constitución de $1991^{8}$ et la loi générale de la culture ${ }^{9}$.

Dans un contexte douloureux, marqué par la récurrence des affrontements armés et par l'absence chronique de représentation étatique en région, ce dialogue, à la fois interrégional et intersectoriel fait émerger un ensemble de propositions qui forgent le socle d'une politique concertée et innovante. La reconnaissance de la grande diversité culturelle de la Colombie devient alors le point de convergence de l'ensemble des revendications. C'est done à partir de cette vaste enquête que le Plan Nacional de Cultura (désormais ici PNC 2000) est élaboré dès l'an 2000.

Il se présente sous la forme d'un document de quatrevingts pages que l'on peut aujourd'hui encore aisément consulter en ligne ${ }^{10}$. Il est cosigné par les plus hautes autorités de l'État en matière de culture: président de la République de Colombie, Andrés Pastrana Arango ; ministre de la Culture, Araceli Morales López; viceministre de la Culture, Martha Mercedes Castrillón Simmonds; secrétaire général, Alfonso Camacho Latorre.

Le PNC 2000 s'efforce de cultiver l'évidence d'une nation colombienne «naturelle», qui se conjugue au singulier, mais dont la très grande diversité «culturelle» fait toute la richesse. Arrêtons-nous sur cette évidence selon laquelle la pluralité culturelle serait une

caractéristique «naturelle» de la Colombie, car c'est de là en effet que les auteurs du rapport déduisent l'impératif politique incombant à l'État colombien de construire une «citoyenneté culturelle démocratique»:

\begin{abstract}
Nous devons construire une citoyenneté culturelle démocratique, non seulement en raison de la nature multiculturelle de notre pays - afin que les différents peuples et les différentes cultures s'y intègrent sans aucune exclusion-mais parce que c'est la seule façon de créer une société plurielle, fondée sur les spécificités, les besoins et les projets de tous les individus, groupes et secteurs. Cette pluralité est la seule garantie de la construction d'un projet collectif commun de coexistence, de paix et d'équité.

(Ministerio de Cultura de Colombia 2001: 13)
\end{abstract}

En faisant de la diversité culturelle le catalyseur d'un destin national, le PNC 2000 invite chacun et chacune à endosser une posture consensuelle à l'égard des notions clés qui alimentent le discours politique: la nation, le développement, la ǵlobalisation, le conflit 11. Cette posture n'est pas née ex abrupto dans le silence d'un cabinet ministériel. Elle vient d'un dialoǵue que le gouvernement Pastrana a instauré avec les acteurs culturels eux-mêmes. En se montrant à l'écoute d'une demande sociale, ce Plan a concouru à faire émerger le principe de diversité à partir duquel l'État a pu imaǵiner une politique culturelle innovante, fédératrice, «qui passe par de nouvelles configurations des relations de pouvoir et des savoirs» (ibid. : 15-16). Une pleine reconnaissance de la pluralité des formes de création culturelle et sociale - et par là même des appartenances qui leur sont liées - est, selon le PNC, l'indice de cette «ouverture démocratique» dont le ministère de la Culture et son organe consultatif, le CNC, vont prôner la mise en œuvre dans ce document pionnier, le PNC 2000. Et ceci de deux façons: d'une part, en renforçant les identités culturelles - soit les identifications culturelles, tant ce mouvement de reconnaissance repose sur l'invention du stéréotype (voir la série des illustrations convoquées dans cet article) -; d'autre part, en proposant des outils permettant de construire ce socle pluriel qui inspirera l'ensemble des secteurs de l'État.

Ces marqueurs de cultures (typologies humaines, musiques, langues, etc.) et leur affichage dans l'espace commun d'une République en partage peut se comprendre, certes, comme un appel à la tolérance. Mais au-delà, il s'agiit bien d'organiser les modalités d'une coexistence possible dans le quotidien de la vie sociale. L'empathie est l'outil de ce vivre-ensemble en ce qu'elle permet de développer «la capacité de se mettre, même temporairement, à la place d'autrui et d'apprécier ses raisons, ses suspicions, ses peurs, ses certitudes, ses besoins et ses recherches» (ibid. : 29). Le PNC fait de la culture un instrument de paix. Première prémisse. Reste alors à construire les dispositifs institutionnels autorisant la mise en œuvre de cette politique. Le PNC 2000 propose que la participation de l'État s'attache à :
4. Les Farc sont fondées en 1964 et nées d'un groupe de guérilleros regroupés autour de Marulanda dès 1956. Au moment des rencontres de Caguán, on évaluait leurs effectifs à plus de quinze mille combattants. Les observateurs notent cet autre fait remarquable: les Farc ont toujours préservé leur cohésion (Pécaut 2006: 9).

5. Cette «zone de détente» s'étend sur $42000 \mathrm{~km}^{2}$ et se trouve dans les départements du Meta et du Caquetá, dont San Vicente del Caguán est la ville la plus importante.

6. Le CNC est un organe consultatif du ministère de la Culture présidé par le ministre de la Culture et composé de représentants du secteur public et de la société civile. Pour plus d'informations, voir les articles 58 et 59 de la loi générale de la culture. Voir Sistema Nacional de Información Cultural, «Sistema Nacional de Cultura» [en ligne], s. d., disponible sur: http://www. sinic.gov.co/SINIC/SNC/Pagina DetalleSNC Participacion. aspx? Id=17\&A REID=5\& SECID $=16 \& S E R I D=\& N I V \_I D=N$ (consulté le 25 mai 2020).

7. Le PNC définit la soutenabilité comme «cet ensemble de pratiques et de stratégies visant à garantir la pérennité, la légitimité et l'avenir des projets culturels en tant que réalités viables faisant partie intégrante de la vie des collectivités» (Ministerio de Cultura de Colombia 2001: 70)

8. La Constitución de 1991 peut être définie comme I'aboutissement institutionnel et politique d'un tournant culturaliste en Colombie (Gros et Dumoulin Kervran, 2011). En effet, le 25 août 1989, de nombreux étudiants organisent une manifestation pacifique, principalementà Bogotá, nommée «la marche du silence». De cette initiative étudiante émerge le mouvement Todavía podemos salvar a Colombia (Nous pouvons encore sauver la Colombie), qui a porté l'idée d'inclure un «septième bulletin» lors des prochaines élections nationales. L'objectif était de consulter le peuple sur la convocation éventuelle d'une Assemblée nationale favorable à la réforme de la Constitution politique. Ce mouvement est nommé La Séptima papeleta, car six scrutins distincts étaient prévus pour le 11 mars 1990: il s'agissait d'élire les maires, les gouverneurs, les conseillers, les députés, les sénateurs et les représentants, pour un total de six bulletins de vote. En ce sens, l'addition du septième bulletin de vote visait I'Assemblée constituante. Voir Quintero Ramírez 2002; Torres Forero 2007; Zuluaga Gil 2017: 63-65.

(Voir suite des notes page 97) 


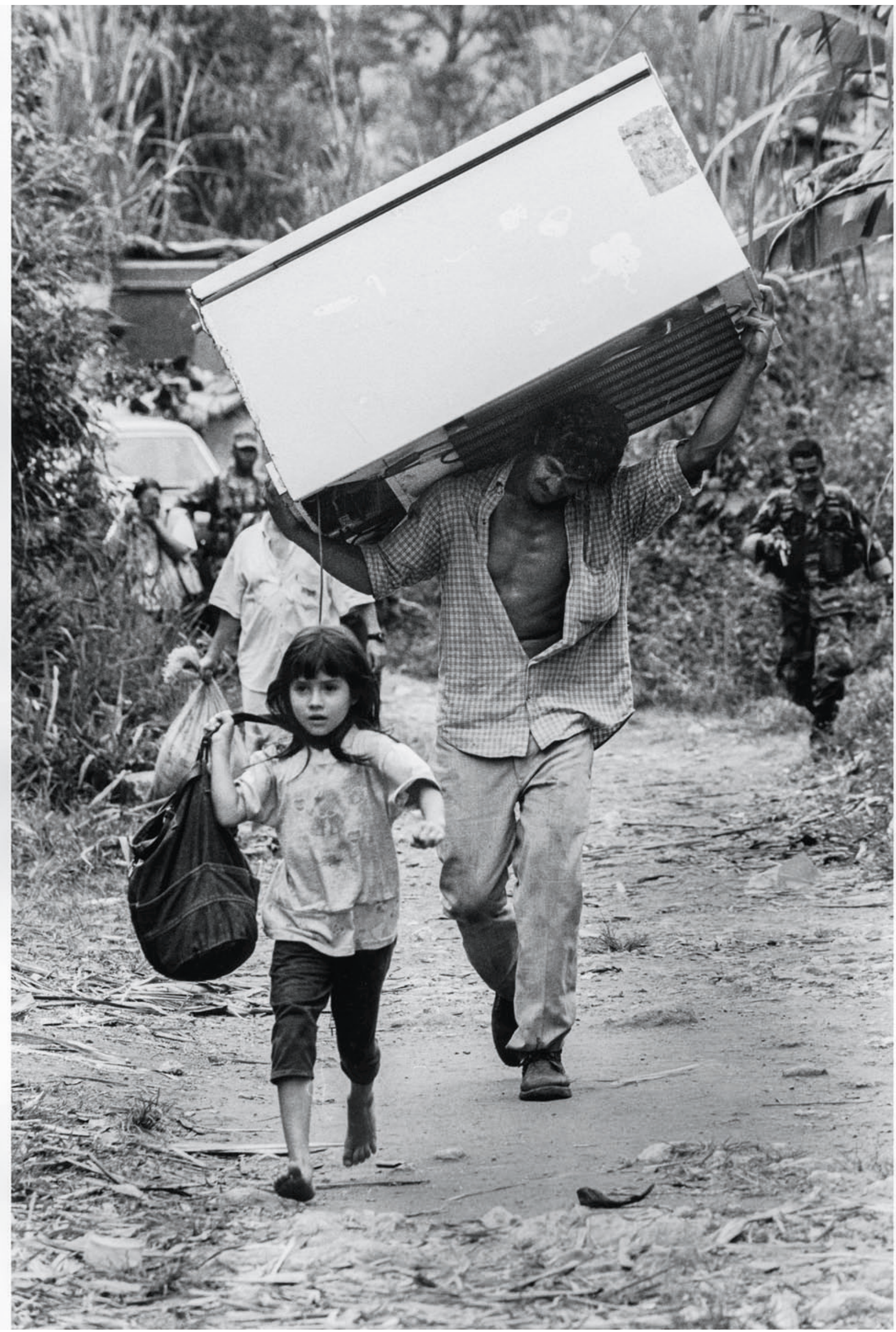


Reconnaître, encourager et stimuler les processus et projets des différents groupes et secteurs de la population, qui contribuent, promeuvent et enrichissent la participation publique dans un cadre de reconnaissance et de respect de la diversité culturelle et de la coexistence des citoyens.

(ibid. : 27)

Ce cadrage inédit stipule en effet que l'État doit soutenir, et non pas diriger, la production culturelle, en élaborant des mécanismes de financement dédiés, adaptés aux divers secteurs culturels qu'il entend promouvoir, et en activant en chacun de ces domaines ce que l'on nommerait aujourd'hui des «droits culturels ${ }^{\mathbf{1 2}}$ » respectueux des critères constitutionnels de justice, d'équité et de transparence.

Rédigé tout au long de l'année 2000, le PNC est présenté publiquement au mois de décembre 2001. Il est alors soumis pour examen au Conpes ${ }^{\mathbf{1 3}}$, autorité de planification nationale au rôle consultatif. Après un an de débats et de délibérations, le Conpes propose de faire du PNC l'un des axes majeurs du développement économique et social du pays. Au mois de mai 2002, il publie les Lineamientos de sostenibilidad del Plan Nacional de Cultura 2001-2010. Le PNG devient une priorité étatique des dix années à venir. L'ensemble des porteurs des traditions musiciennes consultés y voient une marque de reconnaissance et se prennent à imaginer d'ambitieuses actions de développement des pratiques musicales. Lélection d'Álvaro Uribe Vélez en 2002 siǵne l'arrêt officiel de ce processus.

Le PNC ne demeure pas moins l'un des textes de référence de la philosophie politique culturelle colombienne. Il définit les mécanismes qui rendent possible le passage d'une politique culturelle à une forme de gouvernement qui fait de la multiplicité des formes d'appropriation culturelle le fondement de sa culture politique (Álvarez et al. 1998). Après 2002 s'ouvre une époque paradoxale marquée par la résistance des services de l'État: là où les discours officiels vont scander la fin du PNC 2000, les acteurs du secteur culturel vont agír pour sa mise en œuvre.

\section{EL PLAN NACIONAL DE DESARROLLO "HACIA UN ESTADO COMUNITARIO » (2002-2006)}

Le président Uribe entend opérer un changement radical. Le Plan national de développement (PND) qu'il publie en 2002 est une loi de programmation de politique générale confirmant le rôle cardinal que l'État entend assiǵner à la politique culturelle ${ }^{14}$. Le PND 2002-2006 est un document de deux cent quatre-vingtquatre pages publié par le département national de planification (Departamento Nacional de Planeación, DNP) visant à mettre en place, c'est son titre, Un Estado Comunitario. Cet État communautaire est défini dès l'exorde:

\begin{abstract}
Le Plan national de développement ouvre la voie à un État communautaire. Un État participatif qui implique les citoyens dans la réalisation des objectifs sociaux. Un État managérial qui investit dans l'efficacité et l'austérité des ressources publiques. Et un État décentralisé qui privilégie l'autonomie régionale avec transparence, responsabilité politique et participation communautaire.

(DNP 2003: 19)
\end{abstract}

Cette conception de l'État se décline en quatre objectifs : 1) assurer la sécurité démocratique ; 2) promouvoir une croissance économique durable et la création d'emplois; 3) construire l'équité sociale; 4) accroître la transparence et l'efficacité de l'État. Il s'aǵit pour le gouvernement de parvenir à une forme d'équité sociale via trois axes de développement: une «révolution éducative ${ }^{15}$ », un renforcement de la sécurité et un plan social d'envergure nationale en faveur des zones rurales. Pour le dire autrement, l'éducation doit servir de catalyseur pour des actions permettant le maintien de l'ordre et la maîtrise des dépenses publiques afin de rétablir un climat de confiance pour les investisseurs. La Colombie du président Uribe serait un État communautaire à même de garantir la sécurité démocratique ${ }^{\mathbf{1 6}}$.

La résolution du conflit armé par l'éradication du narcotrafic est la priorité de sa politique intérieure. Par sécurité démocratique, il comprend:

l'exercice d'une autorité qui respecte les règles, contient et dissuade les violences et s'engage à respecter les droits de l'homme ainsi que la protection et la promotion des valeurs, de la pluralité et des institutions démocratiques.

(ibid. : 31)

Ce programme est appliqué en ciblant quelques lignes d'action: contrôle du territoire et défense de la souveraineté nationale (ibid.: 32), combat contre le trafic de drogues et le crime orǵanisé (ibid. : 49), renforcement de l'institution judiciaire (ibid. : 60), développement économique des zones en conflit (ibid. : 67), protection et promotion des droits de l'homme et du droit international humanitaire (ibid. : 75), renforcement de la coexistence et des valeurs [sic] (ibid. : 85).

Envisaǵés de cette manière, les attendus du PND visant au «renforcement de la coexistence et des valeurs ${ }^{17}$ » ne sont pas si différents des buts que le PNC se proposait d'atteindre sous la mandature précédente. Il s'agit toujours de «renforcer le tissu social afin que la confiance des citoyens envers leurs institutions soit rétablie, grâce au respect des droits de l'homme, à la promotion du pluralisme et à la participation des citoyens » (ibid. : 85). Et c'est ici que vient se loger l'attention constante prêtée aux pratiques musicales de tradition dans l'ensemble du pays. Cependant, le proǵramme se distingue radicalement du PNC 2000, car la diversité culturelle y sert moins à conjuguer un État au singulier qu'à « consolider l'État communautaire» (ibid.).
9. La loi générale de la culture est le résultat d'un large processus de participation et de consultation citoyenne et intègre trois projets de loi: la création du ministère de la Culture, la mise en place du Système national de la culture et du Conseil national de la culture.

10. Voir Ministerio de Cultura de Colombia 2001

11. Le texte-cadre du PNC entend le conflit comme «l'opposition des intérêts et visions du monde qui résultent de la coexistence dans la diversité» (ibid.:16). Le Plan accepte le conflit comme un élément constitutif de la vie sociale et présuppose qu'une régulation pacifique et créative enrichirait, à partir de la différence, les projets collectifs. Ici, la différence n'est pas un problème à résoudre, mais une chance à saisir.

12. Les droits culturels sont une catégorie de droits de l'homme de nature «prestationnelle», dans la mesure où leur application dépend de normes budgétaires et de procédures (López Daza 2016). Mais ils peuvent être transmués en droits subjectifs. Ces droits sont connus sous le nom de «droits de deuxième génération», car ils reposent sur l'idée que l'être humain doit vivre et se développer dans des conditions sociales, économiques et culturelles conformes à sa dignité. Ils surgissenten réponse à l'utilitarisme libéral de la première génération des droits de l'homme au cours du xix siècle et se consolident au début du xx ${ }^{\mathrm{e}}$ siècle. En Colombie, ils sont définis par la Cour constitutionnelle. Par ailleurs, sans qu'ils y soient explicitement énoncés, la loi de la culture de 1997 prévoit les cadres juridiques d'un ensemble de projets et d'actions institutionnelles en faveur de la reconnaissance et du développement des droits culturels.

13. Le Conseil national de politique économique et sociale est la plus haute autorité de coordination des politiques publiques en Colombie. publiques en Colombie.
C'est un organe consultatif qui supervise le Plan national de développement et examine les documents officiels liés au développementéconomique etsocial du pays. Bien qu'iln'ait et socialdupays. Bien qu'il n'ait aucun pouvoir législatif, il trac I'orientation annuelle du gouvernement en matière de politique économique et sociale. Créé par la loi 19 de 1958, il est placé sous l'autorité du président de la République et composé dece dernier, de tous les ministres, du directeur du département national de la planification et du directeur du département administratif de la science, de la technologie et de l'innovation. Voir DNP s. d.

14. Voir DNP 2003

(Voir suite des notes page 98) 


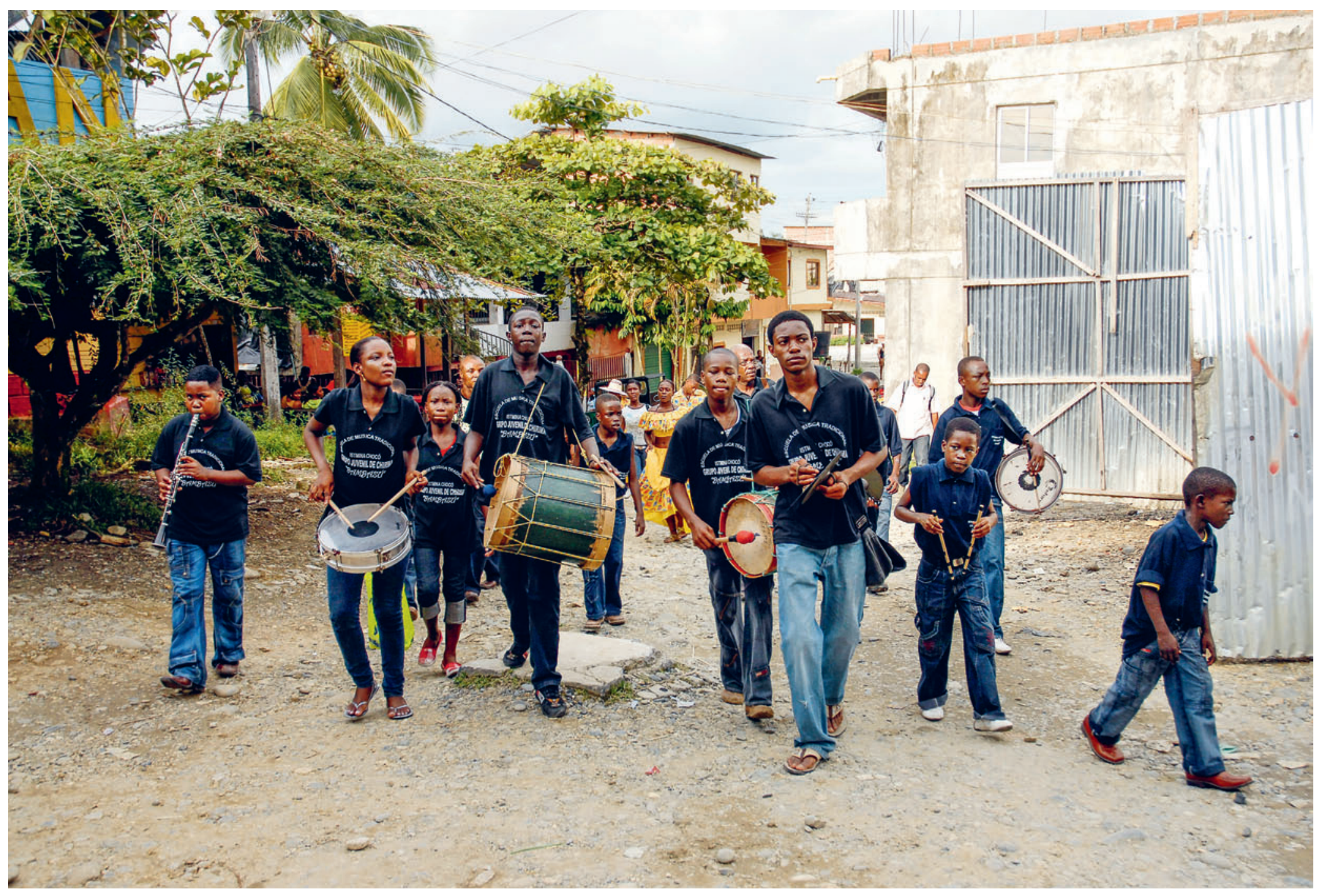

École de musique traditionnelle Groupe juvénile de Chirimía «Bambazú». Istmina, département de Chocó, Colombie, 2008 c) Ministerio de Cultura de Colombia. Photo Alberto Cierra.

15. Pour plus d'informations sur le rôle de l'éducation dans la politique d'Uribe, voir Atehortúa Cruz (2003).

16. C'est en cela, d'ailleurs, que le PND du président que le PND du président de son prédécesseur. L'Estado Comunitario qu'il théorise et met en place ôte à l'Ełat toute responsabilité dans l'élaboration d'une politique sociale, dont il délègue la mise en œuvre aux seules communautés qui auron su se structurer. Selon l'Éta† communautaire, quelques aides étatiques doiven permettre aux communautés, une fois reconnues, de mettre en œuvre des formes d'autogestion: que les plus pauvres d'entre les population autochtones porteuses de traditions gèrent leur pauvreté, avec quelques aides étatiques. Pour des analyses critiques du PND d'Álvaro Uribe Velez, voir infra bibliographie: Bolíva Ramírez 2002; Roldán Luna 2003; Zamudio 2003. Pour les commentaires institutionnels portant sur le PND, voir Hernández Gamarra 2003, DNP 2003

\section{(Voir suite des notes} page 99)
Cette fois encore, «la culture» est promue en outil de cohésion sociale: "La culture est présente dans toutes nos actions, elle enrichit nos droits politiques, sociaux et économiques et constitue le fondement de la vie en commun.» (ibid.: 88).

Or, «la culture est le fondement de la nationalité, il est [donc] nécessaire de mettre en place des programmes nationaux et régionaux qui valorisent et promeuvent les divers processus et les manifestations culturelles qui caractérisent notre pays, ainsi que les initiatives culturelles qui permettent de renforcer la démocratie, le sentiment d'appartenance et la cohésion sociale.» (ibid. : 89)

Entrons plus avant dans le document. Les deux cent quatre-vingt-seize pages du PND se déclinent en cinq chapitres. D'une manière assez étonnante, le PNMC dont il va être question ici est l'un des paraǵraphes du premier chapitre consacré aux manières de garantir "la sécurité démocratique », intitulé «Brindar seguridad democrática» : garantir la sécurité démocratique. Il comprend sept paragraphes:

1. Le contrôle du territoire et la défense de la souveraineté nationale
2. La lutte contre le problème des drogues illicites et du crime organisé

3. Le renforcement de la justice

4. Le développement économique dans les zones de crise et de conflit

5. La protection et promotion des droits de l'homme et du droit humanitaire international

6. Le renforcement de la coexistence et des valeurs

7. La dimension internationale

Le sixième paraǵraphe trace quatre lignes directrices : la diversité culturelle, la lecture, la musique et les institutions :

1. reconnaissance et formation attachées aux valeurs

2. Plan national de lecture et de bibliothèques;

3. Plan national de la musique pour la coexistence;

4. renforcement de l'institutionnalisation culturelle. 


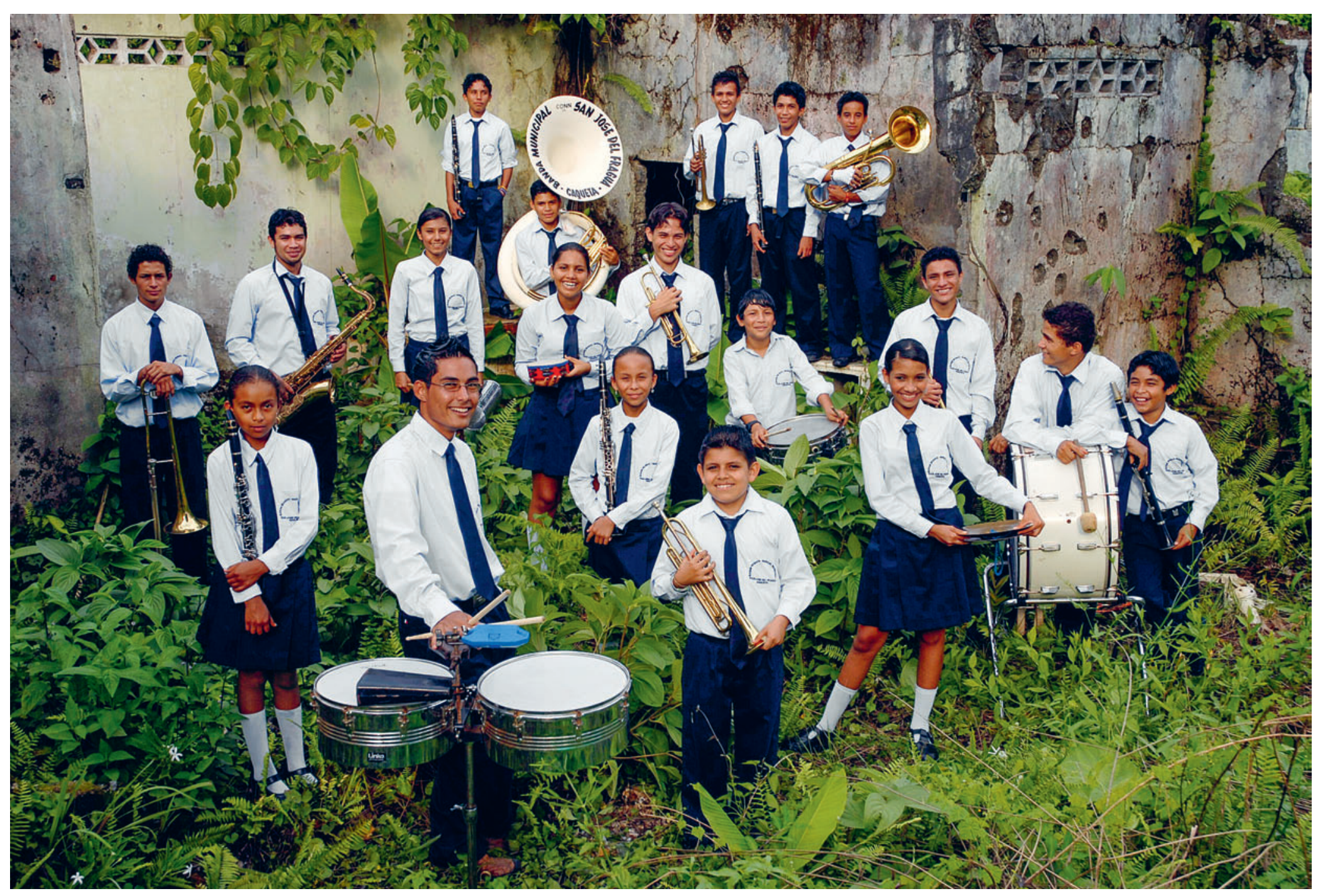

École de musique de San José del Fragua, département de Caquetá, Colombie, 2008 (c) Ministerio de Cultura de Colombia. Photo Alberto Cierra.

Le plan d'action n'est pas détaillé, mais des mesures sont proposées, arǵumentées et chiffrées. Le Plan national de lecture entend soutenir cinq cents bibliothèques publiques et en créer trois cents autres qui profiteront à quatre millions d'habitants, dont les deux tiers se trouvent en zone rurale. Bilan attendu: 2,6 millions d'ouvrages et près de $35 \%$ de lecteurs supplémentaires ainsi qu'un indice de lecture qui passe de 2,4 à 3,5 livres par an. Ces mesures visant les infrastructures s'accompagnent d'un plan de formation professionnelle de cinq mille «promoteurs de lecture». Les mesures sont comparables pour la musique. Selon le plan, la lecture et la musique sont des indices de l'inégale répartition des savoirs dans le pays et de l'inégale accessibilité aux équipements culturels : pas de livres, pas de bibliothèques; pas d'instruments de musique, pas de structures de formation artistique dans ces zones de conflit que fuit la masse inédite des déplacés intérieurs. Pour réparer ces injustices, le PND de 2002 propose de tenir ensemble démocratie et démocratisation culturelles. Dans cette perspective, il s'agit de doter le pays d'instruments dont la pratique permettra «un accès de tous à la culture» (DNP 2003: 89).
Le plan veut promouvoir des formes diversifiées d'identités culturelles et dans le même temps développer les formes participatives. C'est à ce prix que la musique peut devenir un outil de paix dans un pays en guerre. Deuxième prémisse.

La présentation générale du PNMC tient en quatre paǵes à peine (p. 91-93), mais pour les musiciennes et musiciens de Colombie, elles vont s'avérer d'une importance capitale. Elles permettent de définir comme priorité nationale une politique publique dédiée à la musique. Ainsi, en septembre 2003, l'Área de Música de la Dirección de Artes du ministère de la Culture élabore et publie la version définitive de ce programme politique inédit: les quarante-quatre pages de ce nouveau document, consultable en ligne ${ }^{18}$, vont marquer durablement la politique culturelle du pays. La page d'accueil du site affiche une profession de foi immuable:

\section{Le Plan national de la musique a affirmé} que la pratique de la musique est un droit pour tous; c'est une nécessité de garantir des possibilités de développement musical pour tous les enfants et les jeunes du pays sans distinction, car le talent musical
17. Le PND fait une seule fois référence à ce qui doit être entendu au sens de valeurs, soit: «l'éthique, la transparence, I'honnêteté, la justice, la solidarité, le respect de la diversité culturelle et la coopération des citoyens avec les autorités locales, civiles, militaires et de police» (DNP 2003: 87).

18. Voir Ministerio de Cultura de Colombia 2003 


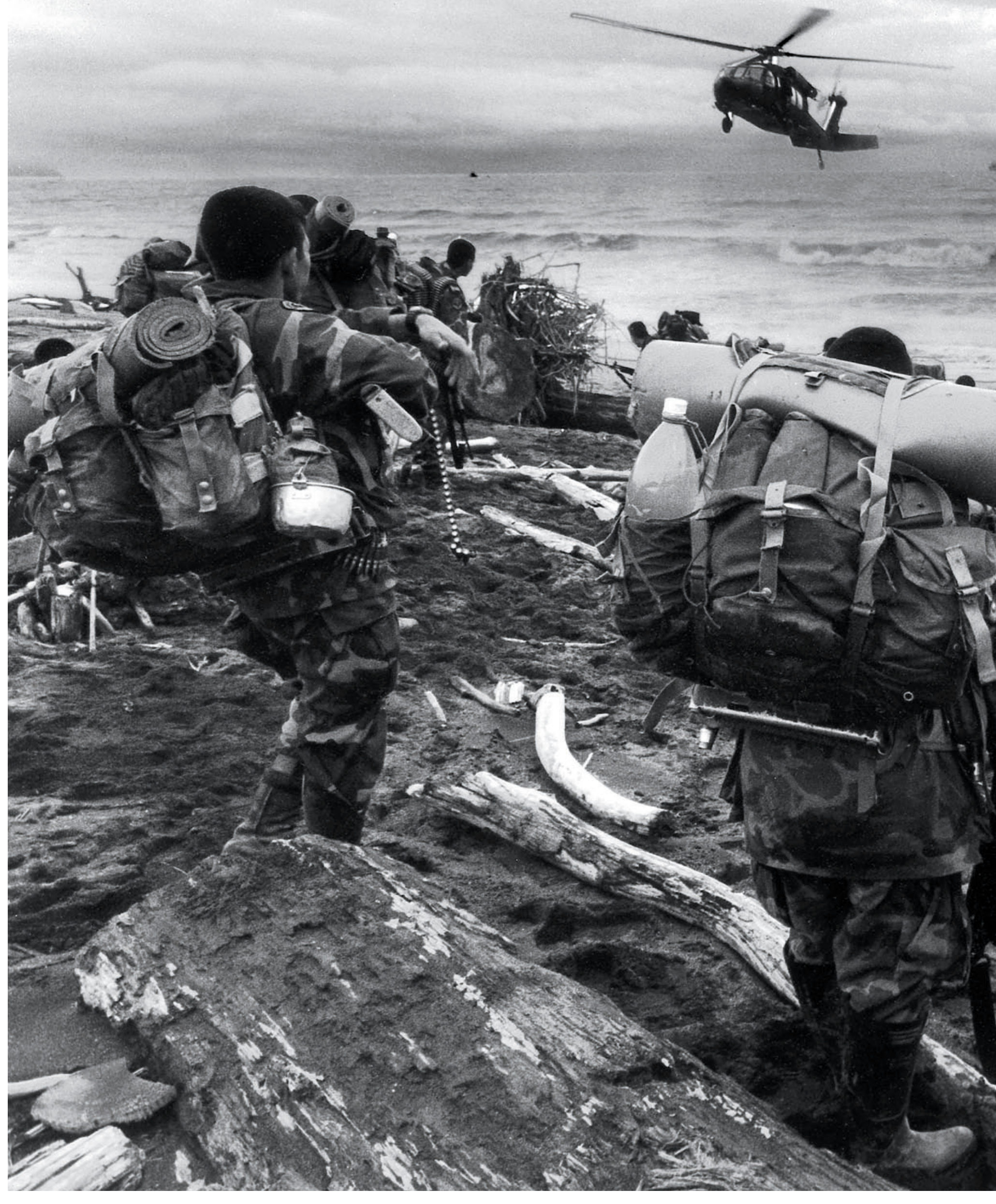




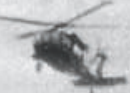

\section{tonenter}

Wuma

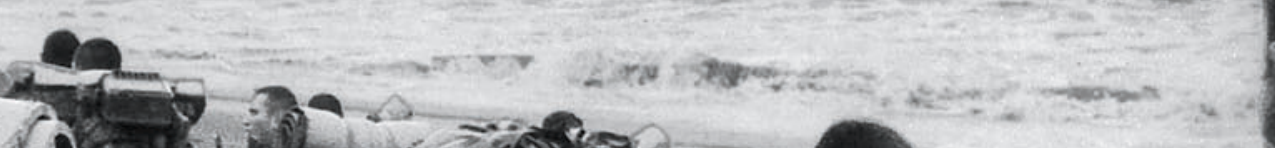

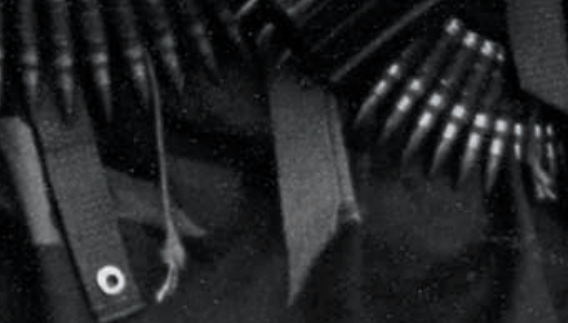


19. À l'intérieur de cette initiative, se trouve le programme «Música para la réconciliación». Voir Ministerio de Cultura de Colombia 2018

20. Voir «Manifiesto Democrático - 100 puntos Álvaro Uribe Vélez» [en ligne], 15 février 2016, disponible sur: https://alvarouribevelez.com. co/primera-campana-2-2/ (consulté en janvier 2019).

21. Voir Torre 2005; Molina Giraldo 2011; Pastrana Buelvas et Vera Pineros 2011; Fierro Castelblanco 2014; Cardona Zuleta 2016: Molina et Blandón 2016.

22. Voir Hayek 1994. Pour une analyse de l'éducation dans le contexte néolibéral, voir Miñana Blasco et Rodríguez 2003.

23. Pour une contextualisatio du conflit, voir Gómez Buendía etal. (2003). n'est pas l'apanage de quelques-uns; c'est un droit culturel universel. De même, il a promu sur le territoire national le principe selon lequel l'expérience et la pratique musicale impulsent la connaissance et la productivité, en influant sur le social et donc l'économique. Il conçoit également la musique comme une dimension constitutive de l'individu, de sa subjectivité et de sa reconnaissance en tant que membre de la communauté.

(Ministerio de Cultura de Colombia s. d.)

Le texte entend « faire de la musique un outil qui contribue au développement social des communautés, avec de meilleures opportunités d'éducation et de loisirs pour les nouvelles générations de Colombiens et la construction de projets collectifs autour de cette expression artistique»(DNP 2003: 92). Le plan s'appuie sur un constat dont les données sont chiffrées :

La Colombie possède le réseau de groupes musicaux le plus important et le plus actif d'Amérique latine. On dénombre 897 formations réparties dans $713 \mathrm{mu}$ nicipalités, ce qui signifie que $64 \%$ des communes ont un groupe de musique. Parmi ces groupes, on estime qu'environ $80 \%$ sont des ensembles de jeunes et d'enfants, les $20 \%$ restants sont animés par des agriculteurs et des musiciens plus âgés.

(ibid.)

Le PNMC entend ainsi valoriser la ǵrande diversité des répertoires et les différences culturelles en créant des outils pour accompagner, rendre visible et professionnaliser l'ensemble de l'activité musicale, en soutenant les musiciens, pédagogues, chercheurs, compositeurs, directeurs d'institution, opérateurs culturels - autant d'engagements rarement reconnus au niveau réǵional. Il s'agit de les doter d'une forme de reconnaissance. Le PNMC entend donc promouvoir un travail de repérage des talents, d'encouragement des pratiques et de pérennisation des formations de musique traditionnelle, des orchestres symphoniques, des orchestres d'harmonie, des chorales et des écoles de musique.

Huit types d'activité deviennent prioritaires: a) consolidation et mise en réseau des associations et des écoles de musique; b) formation de directeurs, d'instrumentistes et d'interprètes ; c) achat d'instruments; d) valorisation des initiatives de participation citoyenne, d'auto-organisation et de gestion associative; e) production et circulation de matériaux qui aident à la diffusion des répertoires; f) recherche, promotion et diffusion du patrimoine musical colombien g) formation des publics; h) circulation des musiciens en promouvant des échanges nationaux et internationaux (ibid. : 92-93).

Pour appuyer cette politique volontariste, le PNMC redéfinit les actions du ministère de la Culture en vue de promouvoir la décentralisation et la participation citoyenne. Pour ce faire, il prévoit de renforcer les proǵrammes du «Réseau national d'orchestres d'enfants et de jeunes Batuta ${ }^{19}$ », du «Réseau d'écoles de musique pour enfants et jeunes de Medellín» et des programmes nationaux de chorales, orchestres d'harmonie et d'écoles de musique traditionnelle, entre autres (ibid.: 93).

Ne perdons pas de vue le cadre de production des textes que nous venons d'analyser. Ils s'inscrivent dans le cercle vertueux des engagements de campaǵne électorale des élections présidentielles, c'est-à-dire dans ce moment singulier où l'offre politique s'ajuste à une demande sociale. Prenons quelque recul.

Le programme présidentiel qui permet en 2002 l'élection dès le premier tour d'Álvaro Uribe à la tête de l'État est présenté pendant la campagne sous la forme d'un «Manifeste démocratique: les 100 points d'Álvaro Uribe $^{20}$ ». Pour de nombreux analystes, ce manifeste est proche d'un certain populisme ${ }^{21}$ qui fait de la culture en général et de la musique en particulier ce que le philosophe britannique Friedrich Hayek appelle des «modules de valorisation [pour une] coexistence pacifique ${ }^{22} »$.

Le point $48 \mathrm{du}$ «Manifeste démocratique» va dans ce sens: "Que les enfants soient touchés par la science, la culture et le sport. Si un enfant serre dans ses bras un instrument de musique, il ne dirigera jamais une arme à feu contre son prochain. » Le président Uribe, leader charismatique et autoritaire, use de symboles culturels forts nourris d'une vision romantique de la dichotomie entre l'art et la guerre: la bonté et le pouvoir transformateur de l'art face à la cruauté, nécessaire, de la guerre. "L'art et la guterre» est le couple infernal qui irriǵue les discours du candidat présidentiel au long de la campaǵne de 2002. Antonio Hernández Gamarra, ex-contrôleur fiscal de la nation (entre 2002 et 2006), estime d'ailleurs que la complémentarité hypothétique entre art et guerre fait en réalité jouer à la culture le rôle d'un dangereux catalyseur destiné à voiler des actions de contrôle et de pouvoir :

Bien des actions envisagées dans ce cadre se révèlent être un catalogue de propositions sans qu'aucun critère ni aucune ligne directrice ne guident leur mise en œuvre, ce qui peut donner lieu à des développements ultérieurs très disparates, voire contradictoires.

(Hernández Gamarra 2003: 25)

Retour au Caǵuán.

\section{GULTURE POLITIQUE ET POLITIQUE GULTURELLE}

L'échec des dialogues de paix du Caǵuán sous le gouvernement Pastrana (voir supra), la prolifération et l'expansion de l'activité guerrillera vers les zones centrales du pays puis l'auǵmentation du nombre de groupes paramilitaires ont changé radicalement la logique territoriale du conflit ${ }^{23}$. Les zones rurales n'étaient plus les seules à souffrir des combats, des massacres et des attentats. Le conflit armé s'est mué en une menace généralisée capable d'atteindre 


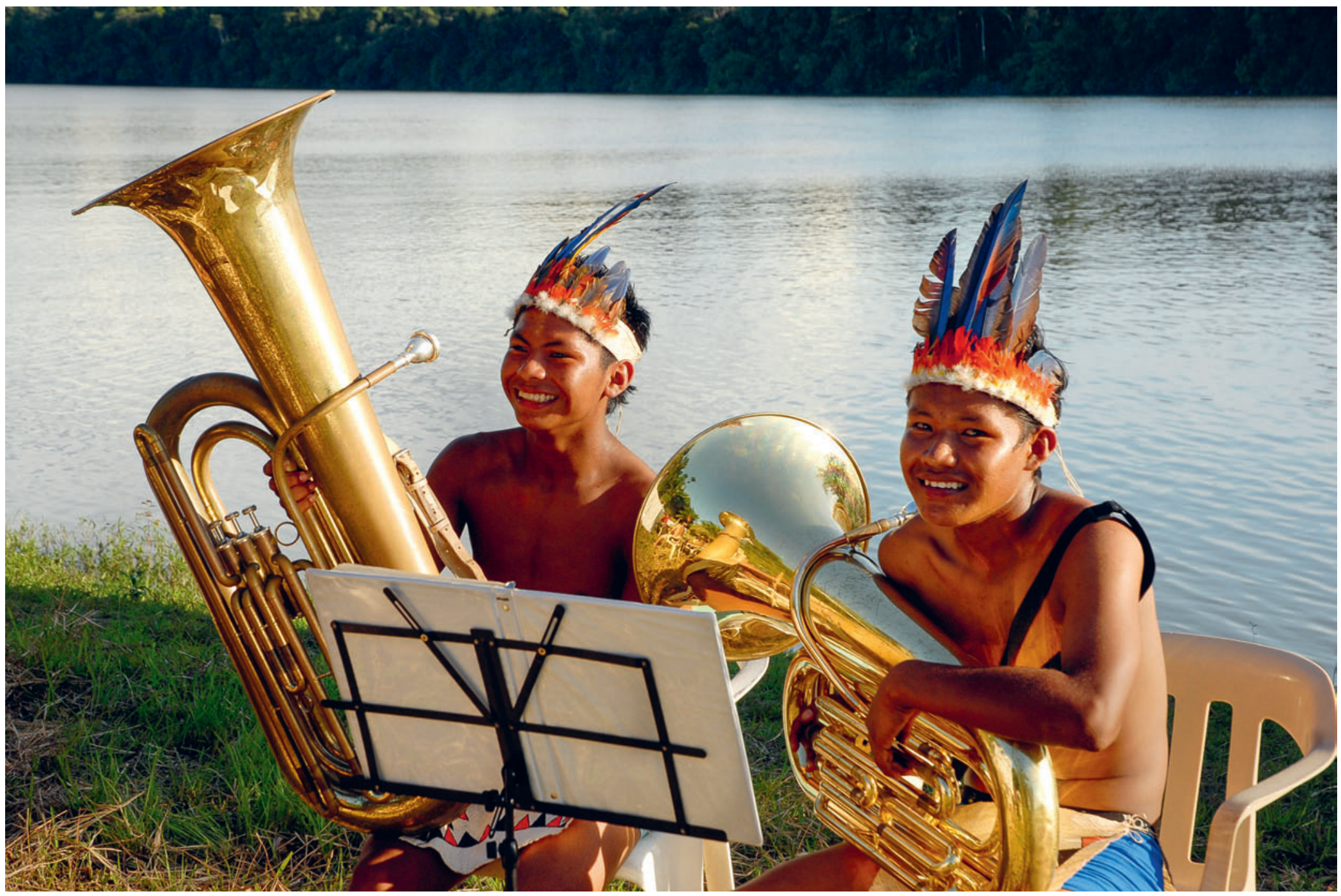

Groupe de l'école municipale pluriethinque de Carurú, département de Vaupés, Colombie, 2008 @ Ministerio de Cultura de Colombia. Photo Alberto Cierra. 


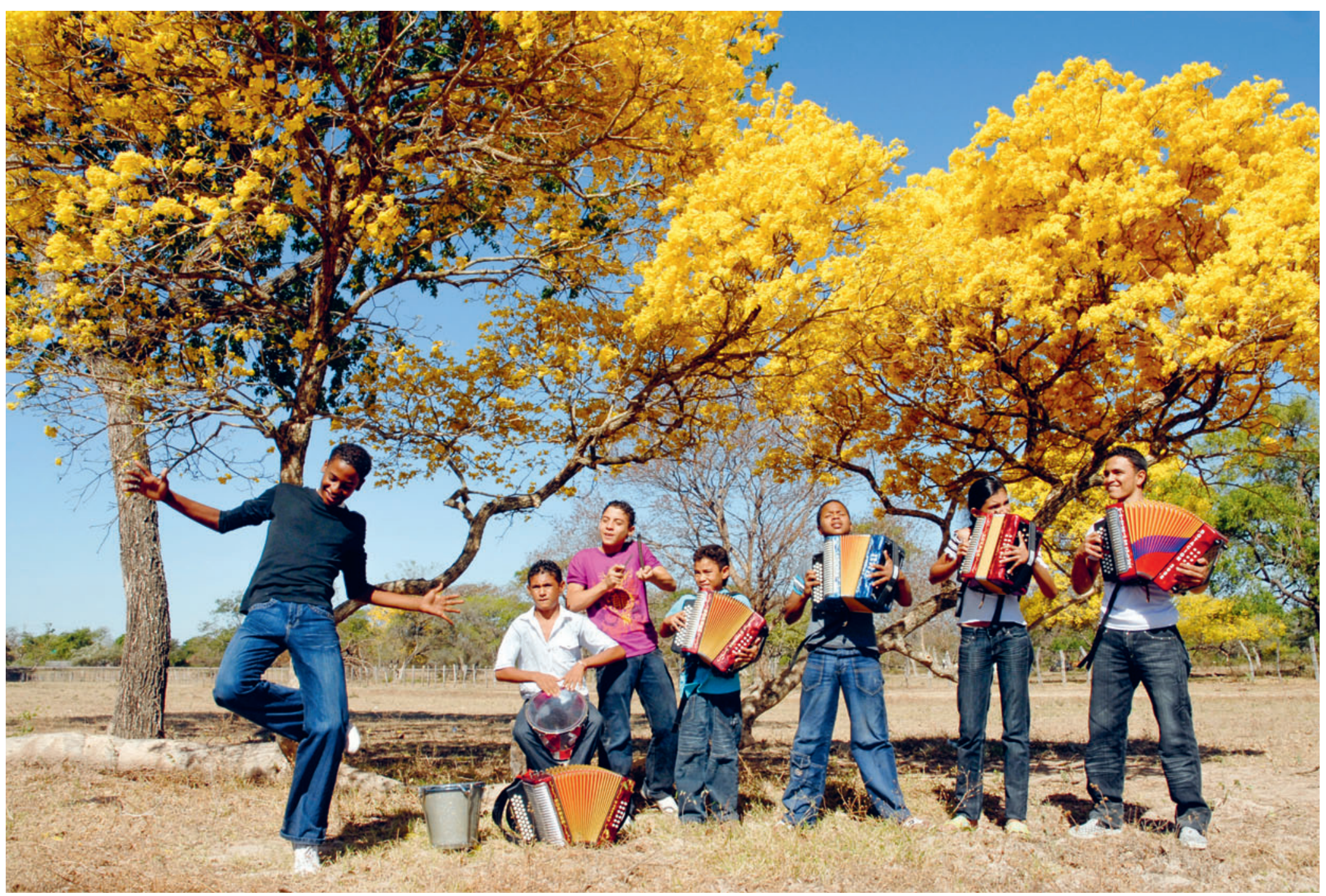

École de musique Alejo Durán, El Paso, département de Cesar, Colombie, 2008 ๑ Ministerio de Cultura de Colombia. Photo Alberto Cierra. 
le développement, les richesses, la sécurité et la vie quotidienne de l'ensemble des citoyens. Dans ce contexte d'inquiétude et d'instabilité, l'un des arǵuments qui ont conduit à la victoire électorale d'Álvaro Uribe Vélez a été celui de la solution militaire et de la négociation des aspects sociaux, économiques et politiques du conflit armé. Le recours à la culture permettait alors d'équilibrer la radicalité du discours politique.

On l'a signalé en ouverture de cet article, le PNC de 2001, puis le PND 2002-2006, tous deux issus de deux formes distinctes d'inquiétude démocratique, font émerger deux représentations de la nation: le PNC invite à l'exercice d'une démocratie participative ; le PND renforce la mise en place d'une démocratie représentative.

La «citoyenneté démocratique culturelle» prônée par le gouvernement Pastrana en 2001 est «une citoyenneté possédant le pouvoir de s'exprimer sans crainte et en communion avec les autres» (Ministerio de Cultura de Colombia 2001: 9). Le plan se lit comme un compendium d'attentes partagées. Les propositions qu'il met au jour, dit le document, sont un décalque des utopies des Colombiens. Elles «renouvellent les solidarités. Les alliances proposées réalisent nos rêves et nous offrent une alternative pour transcender de manière créative et pacifique la violence qui effraie aujourd'hui des millions de personnes» (ibid.).

Ce programme de démocratie participative promu dès le début des années 1990 ne vise pas seulement à sanctuariser des objets patrimoniaux ou à construire une «culture colombienne» composée de marqueurs identitaires figés. Il promeut une culture de paix en mobilisant, dans une forme dynamique, les «traits distinctifs, spirituels, matériels, intellectuels et émotionnels qui caractérisent les groupes humains et qui comprennent, au-delà des arts et des lettres, des modes de vie, des droits de l'homme, des systèmes de valeurs, des traditions et des croyances ${ }^{\mathbf{2 4}}$ ». Le PNC de 2001 fait donc de la culture et des manifestations artistiques les éléments majeurs de sa politique de paix: ce «nouveau projet collectif de nation» ne peut s'envisager autrement que comme «une construction permanente à partir du culturel» (ibid. : 39). Le PNG cherche donc à identifier, puis à développer des pratiques sociales vécues comme des marqueurs identitaires pour les encourager et les institutionnaliser.

Du point de vue des politiques culturelles, le Plan Nacional de Cultura 2002-2010 est une initiative sans précédent. La participation sectorielle, aussi bien au niveau régional qu'à celui des municipalités, puis la dynamique impulsée afin de mobiliser dans l'espace public des manifestations artistiques qui procurent une place à chacun ont permis de construire une «idée d'identité colombienne plurielle». Ce triple mouvement - identification, reconnaissance, mobilisation de la pluralité - a permis la fabrique d'une multiculturalité, inscrivant dans les aǵendas politiques des mécanismes institutionnels de la diversité culturelle (Restrepo et Rojas 2004; Gros et Dumoulin Kervran 2011; Rojas 2011). C'est à l'analyse de ce processus d'institution d'une référence plurielle dans la mémoire colombienne qu'est consacrée la seconde partie de cet article.

\section{LA MUSIQUE POUR GONSTRUIRE LA PAIX?}

La lecture de textes programmatiques conçus au sommet de l'État nous renseigne sur la philosophie politique qui anime nos dirigeants et sur les prérequis de sa mise en œuvre, mais ne suffit pas à mener une analyse anthropologique. Pour cela, il faut aller voir de près. Je creuserai donc maintenant dans deux directions : les pratiques musiciennes des «porteurs de tradition» ciblés par ces deux plans; les modalités techniques de la transformation d'une parole de président en outil de gouvernance administrative par les fonctionnaires d'État.

Si l'on cherche à rencontrer un artiste dont la figure est ancrée localement et la stature rayonne internationalement, c'est bien à San Cayetano, dans le département de Bolívar, sur la côte caraïbe, qu'on la trouve: Petrona Martínez, «papesse hilare du bullerengue colombien ${ }^{25}$ », née en 1938 et «découverte 26» sur la côte caraỉbe grâce au documentaire que la réalisatrice franco-colombienne Lizette Lemoine réalisa en 1997 (Lemoine 1997). Sitôt après cette rencontre, Petrona Martínez enregistre le disque Colombie.

Le bullerengue/Petrona Martínez pour la prestiǵieuse collection Ocora Radio France (Radio France 1998). On la compare volontiers à Cesaria Evora et la voici emportée, à plus de 50 ans, dans ce mouvement de valorisation des traditions musicales de Colombie, jusqu'à sa consécration: une nomination aux Latin Grammy Awards 2010. Depuis lors, Petrona Martínez se produit sur toutes les scènes d'Europe et d'Amérique, elle est l'une des figures charismatiques de ce vaste mouvement de valorisation des traditions. Il en existe bien d'autres: Juan Fernández (gaitero de San Jacinto), José Antonio Torres «Gualajo» (compositeur et joueur de marimba de chonta de Guapi), Francisco Tenorio et Layllis Quiñones (artistes et opérateurs culturels, fondateurs de la Fundación Tumac à Tumaco), Nidia Gongora (cantadora de Timbiquí) et son groupe Canalón...

Ces formes de reconnaissance et de production des figures de la Colombie musicienne ont été possibles grâce à la transformation d'une politique étatique en outils de gouvernance administrative, dont se sont emparés les fonctionnaires et les experts de la culture via des dispositifs institutionnels. Nous voici donc dans les bureaux du ministère de la Culture.

\section{AU MINISTÈRE}

Comme je l'ai évoqué plus haut, dès l'élection d'Álvaro Uribe en 2002, de nouvelles lignes directrices sont mises en œuvre au ministère de la Culture. Il s'aǵit d'élaborer une politique culturelle qui reprenne l'arǵumentaire du «Manifiesto Democrático » sur la lecture et la musique (voir supra note 20), sans pour autant suivre les préceptes définis dans le PNC 2000 et donc, sans mener à terme les lignes directrices du Conpes prévues pour ce plan décennal (voir supra note 13). Comment interpréter cette tension, cet écart entre les discours et la pratique?
24. Congreso de Colombia Ley 397 de 1997 [en ligne], s. d. disponible sur: http://www. sinic.gov.co/SINIC/Sipa Conceptos_Comite_Tecnico/ ley\%20397\%20de\%201997.pdf (consulté le 23 janvier 2016). Le décret portant sur le secteur culturel édité par le ministère de la Culture le 26 mai 2015 va exactement dans le même sens; voir Ministerio de Cultura de Colombia 2015.

25. Voir Gaillard 2004.

26. Pour plus d'informations sur Petrona Martínez, voir Lemoine et Salazar 2013.

\section{(Début des notes} de la page 106)

27. Voir Unesco, «Déclaration universelle de I'UNESCO sur la diversité culturelle» [en ligne], 2 novembre 2001, disponible sur: http://portal.unesco.org/ fr/ev.php-URL_ID=13179\& URL_DO =DO_TOPICGURL_ SECTION $=201 . \mathrm{h}+\mathrm{ml}$ (consultée en avril 2018): «Les droits culturels sont partie intégrante des droits de l'homme, qui sont universels, indissociables et interdépendants.

L'épanouissement d'une diversité créatrice exige la pleine réalisation des droits culturels, tels qu'ils sont définis à l'article 27 de la Déclaration universelle des droits de l'homme et aux articles 13 et 15 du Pacte international relatif aux droits économiques, sociaux et culturels. Toute personne doit ainsi pouvoir s'exprimer, créer et diffuser ses œuvres dans la langue de son choix et en particulier dans sa langue maternelle; toute personne a le droit à une éducation et une formation de qualité qui respectent pleinements on identité culturelle; toute personne doit pouvoir participer à la vie culturelle de son choix et exercer ses propres pratiques culturelles, dans les limites qu'impose le respect des droits de l'homme et des libertés fondamentales.» 
28. Pour une déconstruction de cet imaginaire, voir Lefebvr 1994; Miñana Blasco et Rodríguez 1996, 1997, 1998, 2000, 2003.

\section{Sur le massacre}

d'El Salado, voir Comisión Nacional de Reparación y Reconciliación,

La Masacre de El Salado: Esa

guerra no era nuestra, Bogota

CNRRR/Grupo de Memoria

Histórica, 2010 [en ligne],

disponible sur: http://

centrodememoriahistorica.

gov.co/el-salado-esa-guerra-

no-era-nuestra/ (consulté le 17

janvier 2020). Voir également

«Retour sur les crimes des paramilitaires colombiens», article paru dans La Semana de Bogotá et traduit le

30 octobre 2003 par Courrier international [en ligne] disponible sur: https://www. courrierinternational.com/ 10/09/a-el-salado -le-massacre-est-dans-toutes -les-memoires (consulté le 24 janvier 2020).

\section{(Début des notes de la page 109)}

30. La Fondation folklorique du Pacifique sud Tumac entame ses activités en 1975 pour répondre au besoin de garde d'enfants des familles qui travaillaient sur le marché de Tumaco. En 1979, lorsqu'elle reçoit le soutien de la Fondatio Plan Padrinos, I'organisation est officialisée et la formation artistique devient l'un des piliers de ses activités culturelles et territoriales. La famille Tenorio territoriales. La famille Tenorio la fondation visant à sauvegarde recréer et diffuser la culture afrodescendante à travers l'enseignement et la pratique des musiques, des danses traditionnelles. Depuisson origine, la Fondation Tumac a fortement contribué à la réinsertion de nombreux enfants et jeunes touchés par la violence et le narcotrafic.

31. Ce qui eut d'ailleurs pou effet de produire des harmonie de grande qualité, qui continuent de représenter le pays dans des concours internationaux comme la Banda Sinfónica Juvenil de Santa Rosa de Osos, d'Antioquia, porte-drapeau de la Colombie lors des rencontres

internationales organisées en 2017 en République dominicaine. Voir Santa Rosa de Osos, «Banda Sinfónica Juvenil de Santa Rosa de Osos representa a Colombia en República Dominicana») [en ligne], 02 mai 2017, disponible sur: http://www.santarosa deosos- antioquia.gov.co/ NuestraAlcaldia/Salade Prensa/ Paginas/Banda Sinf\%C3\% B3nica-Juvenil-.aspx (consulté en janvier 2020)
Dans un pays en conflit submergé par la violence et le trafic de drogue, où les contrastes entre groupes sociaux, d'une part, et entre villes et campagnes, d'autre part, accentuent l'inégalité d'accès aux droits culturels stipulés dans la Constitution de 1991 et la loi générale de la culture, musique et lecture deviennent des enjeux de première importance. Correspondant à un ensemble de valeurs majoritairement partagées et acceptées suivant la hiérarchisation du capital symbolique, la lecture et les pratiques musicales constituent les éléments clés d'une rhétorique de persuasion soucieuse d'afficher des valeurs démocratiques de justice, d'éducation et d'accessibilité (Buffon 2002 : 329-354). Toutefois, dans le mode de gouvernance déployé par le président Uribe, musique et lecture s'inscrivent avant tout dans la continuité des logiques éducatives néolibérales développées en Colombie lors des dernières décennies (Miñana Blasco et Rodríguez 2003). L'iconographie que je produis à l'appui de cet article témoigne de cette rhétorique de persuasion: un enfant qui tient un instrument de musique jamais ne pointera une arme à feu sur son prochain.

L'ethnomusicologue Carlos Miñana Blasco, professeur au département d'anthropologie de l'Universidad Nacional de Colombia à Bogotá, interroge de longue date la façon dont l'art est mobilisé dans une rhétorique qui cherche à favoriser les conditions d'une coexistence pacifique. Selon Miñana, la culture, les arts et l'éducation artistique ne sont pas considérés comme des nécessités ou comme des droits constitutifs de la citoyenneté27. L'intérêt que l'État leur porte tient à ce qu'ils apparaissent comme les éléments incontournables des projets de «coexistence», de «résolution des conflits» et «d'éducation à la paix» (Miñana 2006).

Cependant, loin d'opter pour une politique dynamique guidée par une vision transformatrice et créatrice des pratiques artistiques, le gouvernement Uribe adhère à une conception essentialiste des phénomènes culturels où «l'art», la «pratique artistique» ou «l'éducation artistique» devraient être capables, en soi, d'orienter la conduite des personnes vers une forme de coexistence pacifique ${ }^{28}$

Mais alors, si tel était le cas, si la musique était, par décret ontologique, un instrument servant à «fabriquer la paix », comment expliquer qu'elle ait pu jouer un rôle aussi crucial dans ce terrible massacre du Salado qui marque au fer rouge l'histoire contemporaine colombienne?

\section{MUSIQUE POUR UN MASSACRE}

Entre le 16 et le 21 février de l'an 2000, dans le village d'El Salado, dans les Montes de María (Bolívar), au nord de la Colombie, quatre cent cinquante hommes arborant le brassard des Autodéfenses campagnardes de Córdoba et Urabá (Accu), l'un des plus importants groupes paramilitaires du pays, exécutent méticuleusement soixante-six victimes (cinquante-huit de sexe masculin et huit de sexe féminin, dont trois enfants). Voici le témoignage d'un survivant recueilli par la Comisión Nacional de Reparación y Reconciliación, Grupo de Memoria Histórica ${ }^{29}$ :
Ici ils avaient apporté des tambours, des accordéons, ici il y avait un groupe de gaitas, ils avaient envoyé les instruments pour que les gars puissent commencer à jouer, tout cela a été pris en charge par eux. Le jeu, c'était combien ils en tuaient, ils jouaient, ils jouaient des tambours, ils jouaient de l'accordéon et tout, ils sont allés chercher les magnétophones, parce que dans les maisons $i l$ y avait de bons magnnétophones, ils prenaient même les magnétophones, tout ce qui jouait de la musique [...]. Quand ils tuaient, ils jouaient, c'était une fête pour eux. C'était une fête pour eux. Ils ont sorti des tambours de la Casa del Pueblo, ils chantaient après avoir tué... On voyait qu'ils avaient plaisir à tuer.

(Sánchez 2010 : 36-37)

Difficile, après le massacre du Salado, d'imaǵiner qu'une force pacificatrice habiterait la musique «en elle-même». Cette ontologie est contredite par la terrible expérience du massacre. Les propriétés musicales ne sont pas inhérentes aux énoncés acoustiques: la musique est ce que l'on en fait. Dès lors, à l'instar de Carlos Miñana, nous parlons de «processus artistiques » et non «d'art» (Miñana Blasco et Rodríguez 2000 : 105).

Ce renversement de perspective change de manière radicale le regard que l'on peut porter sur le programme politique. Il ne s'aǵit plus, ici, de rechercher des effets de l'art et de l'éducation artistique et culturelle sur la formation des valeurs, mais de questionner les situations dans lesquelles certains processus artistiques et culturels peuvent contribuer à la reconstruction du tissu social. Pour observer cela, retournons à la division de la Musique (Área de Música) du ministère de la Culture.

\section{LES INSTITUTIONS DE L'INTERACTION}

J'emprunte le syntaǵme «institutions de l'interaction» à l'historien Pierre Rosanvallon dans son ouvrage canonique Légitimité démocratique : impartialité, réflexivité, proximité (2008). Dans la partie consacrée à la légitimité de proximité, Rosanvallon suggèere que la légitimité démocratique ne se joue pas seulement au niveau du processus électoral, mais aussi dans les stratégies de gouvernance. Nous allons voir ici comment la direction de la Musique, en charge de la mise en œuvre de la politique culturelle relative au PND 2002-2006 du gouvernement Uribe, va faire en sorte que les attendus du PNC de la mandature précédente soient implémentés dans le PND du gouvernement Uribe, alors même que celui-ci entendait liquider l'héritage de son prédécesseur. Les considérations qui suivent sont basées sur des entretiens que j'ai conduits auprès d'anciens fonctionnaires du ministère de la Culture au sein de l'Área de Música.

Lorsque la ministre María Consuelo Araújo, la viceministre María Adriana Mejía et leurs équipes arrivent au ministère de la Culture sous le mandat du président 


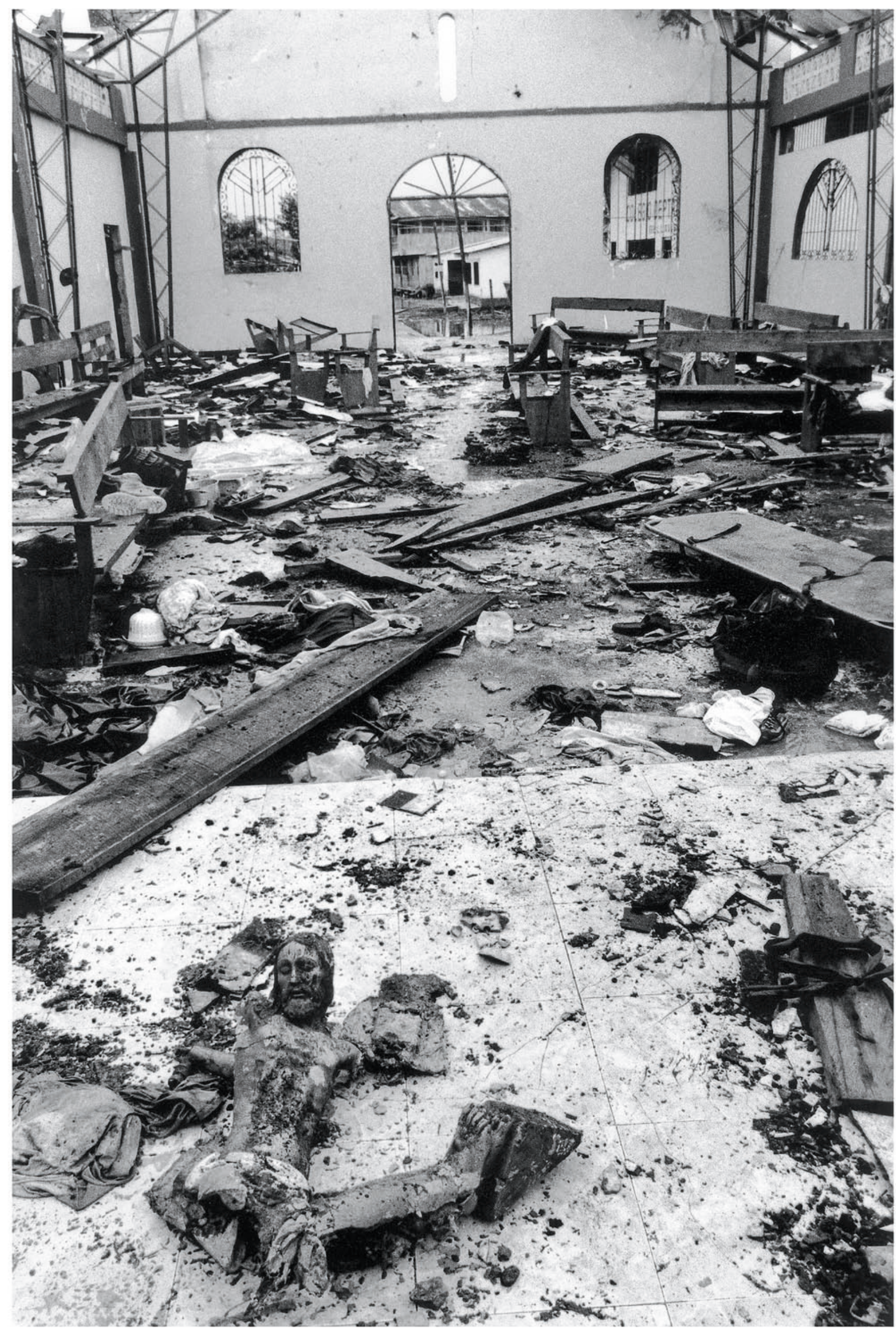




\section{Dossier}

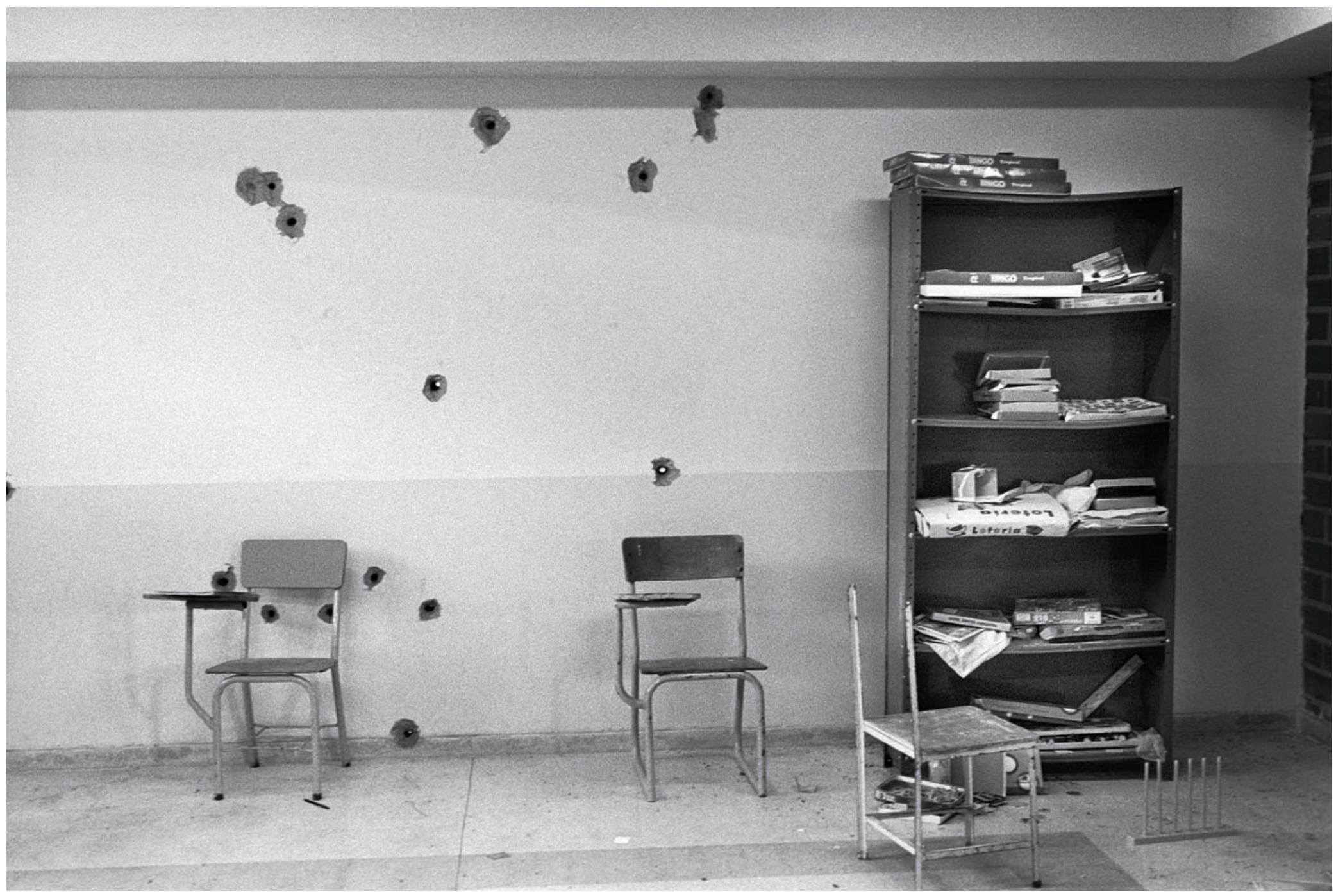

École Pedro J. Gómez, Commune 13, Medellín, octobre 2002 @ Jesús Abad Colorado. 
Uribe en 2002, elles annoncent, dès le mois de septembre, qu'elles entendent mettre un terme au PNC de 2001. Le ministère se concentrera désormais sur deux priorités: la lecture et la musique, c'est-à-dire les bibliothèques publiques et les pratiques musiciennes, cœurs de cible des politiques publiques (voir supra). L'Área de Música de la Dirección de Artes serait en charge du dossier, elle qui jusque-là s'occupait principalement de la mise en œuvre des projets territoriaux liés à la musique à une moindre échelle. Ces dispositifs avaient permis à la famille Tenorio Quiñones et à la Fondation Tumac ${ }^{30}$, par exemple, de conduire un programme de paix par le développement de pratiques artistiques traditionnelles dès la fin des années 1970 à Tumaco, dans l'extrême sud-ouest du pays, sur la côte pacifique (Nariño). Dans cette dynamique de gouvernance, un dialogue de paix avait pu se construire entre un niveau régional et un niveau étatique. Les espoirs étaient grands du côté des groupes de musique traditionnelle. Mais en 2002 «le démon de la centralisation» (Rosanvallon) refait surface. Il ne s'agit plus alors d'encourager une dynamique de la diversité, mais d'uniformiser le pays en essentialisant ses marqueurs de tradition.

Lorsqu'il était gouverneur du département d'Antioquia (1995-1997), le président Álvaro Uribe Vélez avait imaǵiné une politique de la musique centrée sur le Plan Departamental de Bandas Juveniles de Música, conçues sur le modèle de l'orphéon ${ }^{31}$. La politique étatique qui se met en place en 2002 est un décalque de celle conduite par Álvaro Uribe dans le département d'Antioquia.

Or, un tel programme existe déjà, c'est celui qu'a déployé Colcultura, pris ensuite en charge par le ministère lors de sa création en 1997 32. L'Área de Música suǵgère alors à la nouvelle ministre de la Culture de développer un plan national inspiré du programme existant, en y faisant une place prépondérante aux pratiques traditionnelles. Deux modes d'action sont proposés : 1) confier, de manière décentralisée, des outils de formation musicale aux établissements scolaires eux-mêmes; 2) élaborer une offre de pratiques musicales sur le modèle du chant choral, des orchestres d'harmonie, des orchestres symphoniques et des musiques traditionnelles.

Dans un premier temps, le ministère renonce à son programme d'orchestres, mais ne souscrit pas pour autant à la proposition de l'Área de Música. Il entend mettre en œuvre «un plan simple et commun à l'ensemble de l'État ${ }^{33}$ », à l'instar du plan de généralisation de la pratique de la flûte à bec dans le cadre du programme Yamaha Music Latin America, réalisé dans les pays d'Amérique centrale, du Sud et les Caraïbes par le musicien Hernando José Cobo ${ }^{34}$ Cette mesure se heurte à l'opposition des acteurs de la culture en région. L'Área de Música décide alors de les associer à une large réflexion, autour de quelques figures consensuelles de l'action culturelle en matière de musiques traditionnelles : Leonardo Garzón, Hugo Candelario González, Arlington Pardo, Victoriano Valencia, Carlos Rojas, Efraín Franco... Il s'agit de concevoir un arǵumentaire pédaǵogique et un programme d'actions qui rendent justice à la grande diversité des pratiques musiciennes.

En agiissant de la sorte, l'Área de Música invite à mettre en œuvre de manière imaginative, collaborative et décentralisée les piliers du futur plan national dont les grandes lignes doivent se retrouver dans le PND. Il ne s'agit plus pour le ministère de travailler dans les régions, mais de travailler avec les régions.

C'est en procédant de la sorte que l'Área de Música rédige le texte relatif au Plan Nacional de Música para la Convivencia composant le PND 2002-2006, qui prône des mesures de décentralisation et de démocratie participative. C'est par la mobilisation de l'administration culturelle - les institutions de l'interaction qui agissent en concertation avec les acteurs locaux - que le PNMC est venu s'inscrire dans la continuité du texte du PNC de la mandature précédente. Et c'est ainsi que des termes tels que «culture», «multiculturalisme» ou «musiques de tradition» ont été érigés en repères communs d'une nation en partage, offrant aux acteurs locaux des musiques traditionnelles la possibilité, d'une part, de s'essayer à des stratégies inventives renforçant la fabrication du lien social et, d'autre part, d'oser des audaces créatives qui placent désormais les musiques de Colombie sur la scène internationale des musiques du monde.

EHESS, Paris \& UNAL, Bogot jasalpina@gmail.com

a

à

32. En effet, la pratique d'orchestres d'harmonie s'est avérée fondamentale dans les Programas Nacionales, dénomination générique assignée à des actions particulières et éclatées, réalisées par I'Instituto Colombiano de Cultura (Colcultura). En 1993, Colcultura (aujourd'hui ministère de la Culture) a mis en œuvre le Programa Nacional de Bandas. Celui-ci fut renforcé avec la formulation des documents Conpes 2961/97 et 3191/02. Depuis 1999, le Programa de Coros escolares a été appliqué, tandis qu'en 2000, un programme dédié aux musiques

traditionnelles a été mis en $œ u v r e$. En outre, le Conpes 3208/02 a défini les lignes directrices de la politique de la musique symphonique. Ces programmes ne

correspondaient pas à des correspondaient pas a des à des politiques culturelles gouvernementales. Le modèle des Programas Nacionales est formulé et mis en œuvre entre 1993 et 2002. II se construit à l'échelon local et départemental pour rayonner ensuite au niveau national. Ici, justement, les programmes départementaux adaptés aux pratiques d'orchestres d'harmonie ont servi comme point de référence et ont été projetés vers d'autres pratiques musicales, telles que la musique populaire/ traditionnelle et les expressions chorales et vocales. Les critères et mécanismes expérimentés dans les contextes locaux et régionaux ont eu tendance à être identifiés et généralisés en tant qu'orientations et stratégies d'action et d'investissement dans la sphère nationale.

33. Entretien avec un haut fonctionnaire du ministère de la Culture sur les origines du PNMC, Bogotá, 24 février 2017.

34. Hernando José Cobo est un musicien chilien. Issu de I'Universidad de Chile, il étudie la flûte à bec à Trinity College (Dublin), puis à Haslemere età Cali (Colombie) avec François Dometsch. Après une carrière de soliste en Amérique du Sud pour l'essentiel, il travaille avec la Fondation Canto por la Vida à l'École de musique de Ginebra, près de Cali, où il dirige le Centre de documentation musicale de Ginebra (CDMG). Il est «musicien Yamaha $a$, responsable de la
Yons conception et de la direction académique des programmes de pédagogie de la flûte à bec de Yamaha Music Latin America destinés aux professeurs de musique d'Amérique du Sud, centrale et des Caraïbes. Il fait partie du comité académique des congrès $M[A] C$ de la musique colombienne. Son programme pédagogique vise à répandre les flûtes Yamaha dans toute l'Amérique. Voir «Hernando José Cobo Plata» [en ligne], s. d., disponible sur: http://flautasdulces.bansbach$\mathrm{cr} . \mathrm{com} /$ indexphp?option $=\mathrm{com}$ contenteview =articlegtid=2:he contenteview=articleetid $=2: \mathrm{h}$ rnando-jose-cobo-plata\& catid
10\&ltemid=101 (consulté en janvier 2020). 
Bibliographie

Álvarez, Sonia E., Dagnino, Evelina, et Escobar, Arturo

1998 Cultures of politics/ politics of cultures: Re-visioning Latin American Social Movements. Boulder/Oxford, Westview Press.

Angarita Cañas, Pablo Emilio 2011 Seguridad democrática: lo invisible de un régimen político y económico.

Universidad de Antioquia, Medellín, Siǵlo del Hombre Editores.

\section{Atehortúa Cruz, Adolfo}

2003 «La "Revolución

Educativa": momentos

y perspectivas ", Revista Colombiana de Educación 44 [en liǵne], disponible sur : https://revistas.pedagogica. edu.co/index.php/RCE/article/ view/7765/6260

(consulté en mai 2020).

Bolívar Ramírez, Ingrid 2002 «El estado comunitario: más administración y menos política », Revista Foro 46 $18-24$.

\section{Buffon, Bertrand}

2002 La Parole persuasive: théorie et pratique de l'argumentation rhétorique. Paris, Presses universitaires de France.

\section{Cante, Freddy}

2003 «Los límites sociales de la seguridad democrática Cuadernos de Economía 39. 204-214.

\section{Cardona Zuleta Luz Margarita}

2016 La culebra sigue viva: miedo y política: el ascenso de Álvaro Uribe al poder presidencial en Colombia (2002-2010). Medellín, Universidad Nacional de Colombia.

\section{Consejo Nacional de Planeación (CNP)} 2003 Colombia se pronuncia sobre el plan nacional de desarrollo «Hacia un Estado Comunitario", 2002-2006. Bogotá, CNP.

\section{Departamento Nacional} de Planeación (DNP)

Sans date «El Consejo Nacional de Política Económica y Social, CONPES " [en ligne], disponible sur: https:// www.dnp.gov.co/CONPES/ Pagiinas/conpes.aspx (consulté en novembre 2018). 2003 Plan Nacional de Desarrollo 2002-2006: Hacia un Estado Comunitario Álvaro Uribe Vélez [en ligne], disponible sur: https:// colaboracion.dnp.gov.co/CDT/ PND/PND.pdf (consulté en novembre 2018)
Espinosa Zuluaga, Andres Felipe

2017 «Confiǵuración de la política de Seguridad Democrática. " Mémoire de master en politiques publiques, Bogotá, Universidad Nacional de

Colombia.

Fierro Castelblanco, Marta Inés

2014 «Álvaro Uribe Vélez: Populismo y Neopopulismo» Análisis Político 81: 127-147.

\section{Gaillard, Florence}

2004 «etrona, papesse hilare du bullerengue colombien », Le Temps [en liǵne], 22 juillet, disponible sur: https://www. letemps.ch/culture/petronapapesse-hilare-bullerengue-colombien (consulté en janvier 2020).

Gómez Buendía, Hernando, Vicente de Roux, Carlos,

Franche, Marc-André, Rubio Serrano, Rocío, et Uribe López, Mauricio

2003 El conflicto, callejón con salida: Informe Nacional de Desarrollo Humano para Colombia 2003. Bogotá, Pnud.

\section{Gros, Christian et}

Dumoulin Kervran, David

2011 Le Multiculturalisme au concret : un modèle latino-américain? Paris, Presses

Sorbonne nouvelle.

Hayek, Friedrich August 1994 La Constitution de la liberté. Paris, Litec.

Hernández Gamarra, Antonio 2003 Evaluación del proyecto de ley por la cual se expide el Plan Nacional de Desarrollo:

«Hacia un estado comunitario Bogotá, Imprenta Nacional.

\section{Leal Buitrago, Francisco}

2002 La seguridad nacional a la deriva: del Frente Nacional a la posguerra fría. Bogotál Quito, Alfaomega,CesoUniandes/Flacso.

2006 La política de seguridad democrática 2002-2005. Iepri, Universidad Nacional de Colombia.

\section{Lefebvre, Noémi}

1994 «Éducation musicale et identité nationale en Allemaǵne et en France». Thèse de doctorat en science politique, université PierreMendès-France, Grenoble.

\section{Lemoine, Lizette}

et Salazar, Jaime Andres

2013 «iAy Petronita, la vida vale la pena!: semblanza de la cantadora Petrona Martínez ». Nómadas, n 39: 217-228.

\section{López Daza, Germán}

2016 «Constitution et droits sociaux. $31^{\mathrm{e}}$ Table ronde internationale des 4 et 5 septembre 2015: Colombie», Annuaire international de justice constitutionnelle 2015 . 189-202.
Miñana Blasco, Carlos et Rodríguez, José Gregorio 1996 «La educación artística en la educación básica y media », Educacion y cultura 41: 33-40.

1997 «Educación artística en la educación básica. Elementos para un debate», in Jairo Santa et Carlos Miñana Blaseo (dir.), Pédagogías artísticas. Bogotá, Colcultura : 47-60.

1998 "No sólo de estética vive el arte», Academia Superior de Artes de Bogotá 1 : 47-60.

2000 «Formación artística: elementos para un debate», in Formación artística y cultural. Memorias del Primer Seminario. Bogotá, ministère de la Culture: 100-121.

2003 «La educación en el contexto neoliberal », in $L a$ falacia neoliberal: critica y alternativas. Bogotá, Universidad Nacional de Colombia: 285-321.

\section{Miñana, Carlos}

2006 «Formación artística y

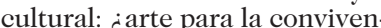
cia? » in Marcela Giraldo (dir.), VII Encuentro para la promoción y difusión del patrimonio inmaterial de países iberoamericanos: gestión del patrimonio inmaterial y la diversidad cultural. Bogotá, Unesco 165-198.

\section{Ministerio de Cultura} de Colombia

Sans date Plan Nacional de Música para la Convivencia [en ligne], disponible sur: https://www.mincultura.gov.co/ areas/artes/planes-y-programas/ pnme/Paginas/default.aspx 2001 Plan Nacional de Cultura 2001-2010: hacia una ciudadanía democrática cultural. Un plan colectivo desde y para un país plural [en ligne], disponible sur: https://www.mincultura.gov. co/planes-y-programas/Planes/ plan\%20nacional\%20de\%20 cultura/Documents/DocNews No371DocumentNo504.PDF (consulté le 12 janvier 2019). 2003 Plan Nacional de Música para la Convivencia [en ligne] disponible sur: https://www. mincultura.gov.co/SiteAssets/ Artes/PLAN\%20NACIONAL\% 20DE\%20MUSICA\%20PARA \%20LA\%20CONVIVENCIA.pdf (consulté en février 2020).

2015 Decreto Único Reglamentario del Sector Cultural 1080 de 2015 [en liǵne], 26 mai, disponible sur : http://www mincultura.gov.co/prensa/ noticias/Documents/Gestion-humana/DECRETO\%20 1080\%20DEL\%2026\%20DE\%20 MAYO\%20DE\%202015\%20-\%20 Sector\%20Cultura.pdf (consulté en décembre 2019).

2018 «Música para la Reconciliación: un ejercicio de inclusión social desde el arte » [en ligne], disponible sur: https://www mincultura. gov.co/prensa/publicaciones/ gov.co/prensa/publicaciones/
Paginas/Música-para-la-ReconPaǵinas/Música-para-la-Recon-
ciliación-un-ejercicio-de-inclusión-social-desde-el-arte.aspx (consulté en janvier 2019).

Molina Giraldo, Jesús María

2011 La identificación de los colombianos con Álvaro Uribe Vélez: del cálculo de los discursos al goce del fuego cruzado. Mémoire de master en sciences humaines, Bogotá Universidad Nacional de

Colombia

Molina, Javier A. et Blandón, Laura C.

2016 «La construcción de pueblo en el populismo: análisi al discurso de un presidente en Colombia (2002 - 2010)», Revista Cientifica Guillermo de Ockham 14 (2) : 165-173.

\section{Moreno, Álvaro}

et García, Fernando

2003 « El estado comunitario: una aproximación a las bases filosóficas », Cuadernos de Economía 39: 195-202.

\section{Pachón, Mónica}

2009 «Colombia 2008: éxitos, peligros y desaciertos de la política de seguridad democrática de la administración uribe»

Revista de ciencia política (Santiago) 29 (2) : 327-353.

Pastrana Buelvas, Eduardo et Vera Pineros, Diego

2011 «La estrateǵia populista en la política exterior de Álvaro Uribe», Papel politico 2 


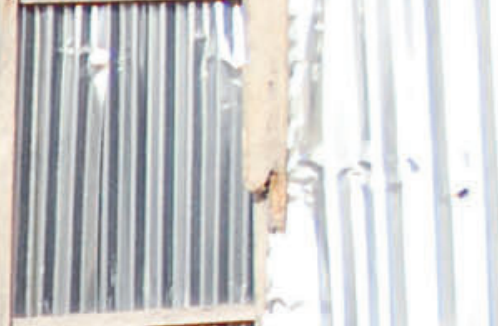

